\title{
Assessment Criterion for Heat Transfer Deterioration of Supercritical Fluids
}

\author{
JI cuilian ${ }^{1,2}$ a , HAN Jitian ${ }^{1, b^{*}}$, CHEN Ran ${ }^{2, c}$ and ZHANG Tao ${ }^{1, d}$ \\ ${ }^{1}$ School of Energy and Power Engineering, Shandong University, Jinan, Shandong, China \\ ${ }^{2}$ Shandong Urban Construction Vocational College, Jinan, Shandong, China \\ ajicuilian75@163.com, bjthan@sdu.edu.cn, 'chr_hl@163.com, 760662923@qq.com
}

Keywords: heat transfer deterioration; supercritical fluid; criterion.

Abstract. In order to enlarge the application scope of the existing criteria for the heat transfer deterioration, the criteria of heat transfer deterioration was assessed by using the method of mechanism analysis and experimental data available in the literature. The obtained results indicated that the criteria based on $\mathrm{q}=\mathrm{f}(\mathrm{G}, \mathrm{D})$ are more useful for practical applications.

\section{Introduction}

Study on heat transfer of supercritical fluids can be traced back to the 1930s. To date, a variety of experimental results have shown that the heat transfer deterioration in supercritical fluids was apt to occur in the vicinity of the proposed critical point, low mass flow, high heat flux and upward mobility ${ }^{[1]}$. Heat transfer coefficient (HTC) peak appeared mainly near the proposed critical point, and might change with the pressure and temperature. Shitsman ${ }^{[2]}$ first reported the experimental results for heat transfer deterioration of supercritical water, showing that with heat flux increased gradually and the other conditions remaining unchanged, the wall temperature rose suddenly in a certain position before a critical point, then reached a peak, and reduced gradually if heat flux was above a certain value. In addition, it is observed that the higher heat flux is, the larger wall temperature peak is. In recent years, the advanced numerical methods ${ }^{[3]}$ and Laser Doppler testing methods were adopted to explore the mechanism of heat transfer deterioration ${ }^{[4]}$. The results indicate that the heat transfer deterioration usually occurs when the bulk temperature is lower than the wall temperature, and the wall temperature is simultaneously higher than the proposed critical temperature. The heat transfer deterioration of supercritical fluids may be divided into three categories: mixed convection deterioration, forced convection heat transfer deterioration and heat transfer deterioration caused by entrance thermal effects ${ }^{[5]}$.

In this paper, the criteria available for heat transfer deterioration of supercritical fluids were discussed. Their applicability for practical uses was assessed by the collected experimental data.

\section{Mechanism of Heat Transfer Deterioration}

The increment of the wall temperature under supercritical pressure conditions is not severe compared to that under subcritical pressure conditions when the heat transfer deterioration occurs. So it is not very clear how to determine the criterion of heat transfer deterioration under supercritical pressure conditions. The criteria of heat transfer deterioration are generally grouped into two categories: one based on ratio of heat transfer coefficients and another on the wall temperatures.

The ratio of heat transfer coefficient (HTC, $\alpha$ ) is expressed as:

$$
\frac{\alpha}{\alpha_{0}}=c, \quad \alpha_{0}=0.023 \operatorname{Re}_{b}{ }^{0.8} \operatorname{Pr}_{b}^{0.4} \frac{\lambda}{d}
$$

As shown in Fig.1(a), the HTC prediction results were consistent with one of Dittus-Boelter equation in the low heat load (close to zero). With increase in the heat load, the HTC peak moved toward lower bulk temperatures, and then reduced the peak amplitude. As shown in Fig.1(b), the HTC ratio was close to unity with increase in the bulk temperature. When the HTC ratio reached a maximum, the corresponding bulk temperature was still far from the quasi-critical point. With bulk temperatures close to quasi-critical value, the HTC ratio fallen. With the bulk temperature exceeded 
the quasi-critical point, the ratio tended to unity again. It is considered that the area of the HTC ratio more than unity as the heat transfer enhancement and area of the HTC ratio less than 0.5 as the heat transfer deterioration [6].

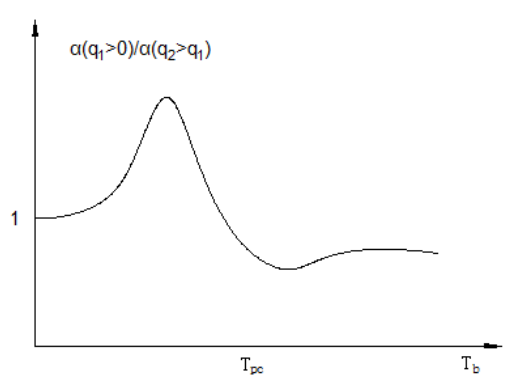

(a) Effect of heat fluxes on HTC

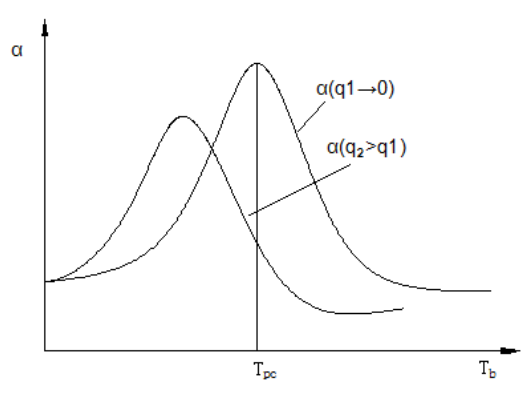

(b) HTC Ratio

Fig. 1 The relationship between heat transfer coefficient and temperature

Another method is to take the wall temperature as a measure standard. The heat transfer deterioration occurs when the wall temperature is beyond a certain temperature.

$$
T_{W}>T_{0}
$$

As shown in Fig.2, under the heat flux control condition, very small increase in heat flux leads to substantial increase in wall temperature (local increase or continued soaring).

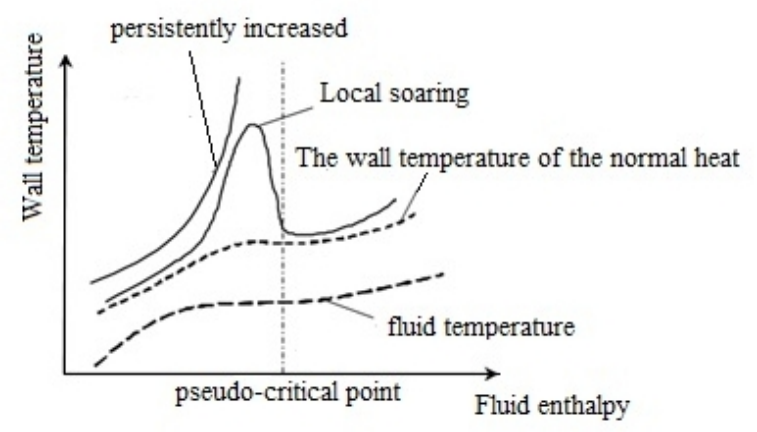

Fig.2 Wall temperature distribution of heat transfer deterioration

\section{Assessment of the heat transfer deterioration criteria}

Most of the heat transfer deterioration criteria are established based on the experimental data, as shown in Table 1 except Li's [10]. The heat transfer deterioration criteria in Table 1 are often used in the design of supercritical boilers.

Table 1 the criterion of heat transfer deterioration

\begin{tabular}{|l|l|l|l|}
\hline Author & $\begin{array}{l}\text { Experimental } \\
\text { conditions }\end{array}$ & $\begin{array}{l}\text { Heat transfer } \\
\text { deterioration criteria }\end{array}$ & Judgment condition \\
\hline Styrikovich[7] & $\begin{array}{l}\mathrm{d}=22 \mathrm{~mm}, \\
\mathrm{p}=24.1 \mathrm{MPa},\end{array}$ & $q / G>0.58 \mathrm{~kJ} / \mathrm{kg}$ & $\begin{array}{l}\text { The outer wall temperature exceeds } \\
580^{\circ} \mathrm{C} \text { as standard of heat transfer } \\
\text { deterioration }\end{array}$ \\
\hline Yamagata[8] & $\begin{array}{l}\mathrm{d}=8 \sim 10 \mathrm{~mm}, \\
\mathrm{p}=22.6 \sim 29.4 \mathrm{MPa}\end{array}$ & $q / G^{1.2}>0.2 \mathrm{~kJ} / \mathrm{kg}$ & $\begin{array}{l}\mathrm{T}_{\mathrm{b}}=230-540^{\circ} \mathrm{C}, \mathrm{G}=310-1830 \mathrm{~kg} \mathrm{~m} \mathrm{~s}^{-2} \\
\mathrm{~s}^{-1}, \mathrm{q}=116 \sim 930 \mathrm{kWm}\end{array}$ \\
\hline Mokry [9] & $\mathrm{d}=10 \mathrm{~mm}, \mathrm{P}=24 \mathrm{MPa}$ & $q>(0.745 G-58.97)$ & $\begin{array}{l}\mathrm{T}_{\mathrm{b}}=320-350^{\circ} \mathrm{C}, \mathrm{q}=70 \sim 1250 \mathrm{~kW} \mathrm{~m}^{-2}, \\
\mathrm{G}=200 \sim 1500 \mathrm{~kg} \mathrm{~m}^{-2} \mathrm{~s}^{-1}\end{array}$ \\
\hline Li [10] & $\begin{array}{l}\mathrm{d}=7.5-38.1 \mathrm{~mm}, \\
\mathrm{p}=22.5-31 \mathrm{MPa}\end{array}$ & $q>d\left(0.36 \frac{G}{d}-1.1\right)^{1.21}$ & $\begin{array}{l}\mathrm{q}=90-1160 \mathrm{kWm}^{-2}, \\
\mathrm{G}=200-1600 \mathrm{kgm}^{-2} \mathrm{~s}^{-1}\end{array}$ \\
\hline
\end{tabular}


As Fig.3 shown that these criteria were verified by the experimental data [11-13]. the criterion application ranges based on function $q=f(G)$ is limited to a very small diameters. The predictive accuracy was significantly lower for the large diameters; but Li's criterion is better than the others. The reason is that Li's criterion was based on both the mass flow rates and pipe diameters by a function of $q=f(G, d)$. It is observed that the larger the diameter is, the more is prone to heat transfer deterioration.

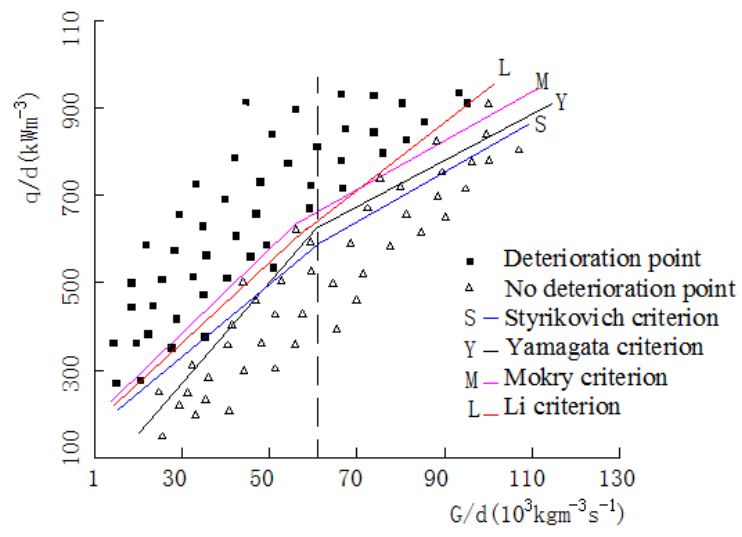

Fig.3 Criterion comparison among experimental data $(\mathrm{d}=5 \sim 40 \mathrm{~mm})$

Another criterion of heat transfer deterioration was developed based on certain assumptions. It is considered that the heat transfer deterioration was caused mainly by the buoyancy and acceleration effects and changes in physical properties, which were resulted from the temperature differences between working medium and the wall temperatures, geometric parameters and other factors.

Table 2 Heat transfer deterioration Criteria based on assumptions

\begin{tabular}{|l|l|l|}
\hline Author & Heat transfer deterioration criteria & Application scope \\
\hline Kondratev[14] & $q_{H T}^{\max }=5.815 \times 10^{-17} \operatorname{Re}_{b}^{1.7}(p / 0.101325)^{4.5}$ & $\begin{array}{l}\mathrm{P}=23.3-30.4 \mathrm{Mpa} ; \\
R e_{\mathrm{b}}=(30-100) \times 10^{3} ; \\
\mathrm{q}=116.3-1163 \mathrm{~kW} / \mathrm{m}^{2}\end{array}$ \\
\hline & $\begin{array}{c}(q / G)_{h t d}=1.3 /\left[\left(t_{p c}-t_{b}\right) c_{p b}(\xi / 8)\right. \\
\left.\left(v_{W} / v_{p c}\right)^{1.3}\right]\end{array}$ & unmentioned \\
Petukhov[15] & $\mathrm{q}=\frac{q_{W}}{\rho u}\left(\beta / C_{p}\right)_{m} / \sqrt{\xi_{0} / 8} \geq 3.4 \times 10^{-2}$ & \\
\hline Protopopov[16] & $\begin{array}{c}(q / G)_{h t d}=1.3 /\left[\left(t_{p c}-t_{b}\right) c_{p b}(\xi / 8)\right. \\
\left.\left(v_{W} / v_{p c}\right)^{1.3}\right]\end{array}$ & $t_{b}<t_{p c}<t_{W}$ \\
\hline
\end{tabular}

It is noted that a disadvantage of the criteria listed in Table 2 is that the wall temperature is needed to previously given and the predictive accuracy of the criteria depends on the accuracy of heat-transfer coefficient correlation, resulting in inconvenient in use of the criteria [17].

\section{Summary}

The heat transfer deterioration criteria for supercritical fluids were discussed in two categories. The mechanism of heat transfer deterioration of supercritical fluids was analyzed. The existing correlations available in the literature were assessed by the collected experimental data. It is concluded that the criteria based on function $q=f(G, d)$ are more useful for practical applications.

\section{ACKNOWLEDGMENTS}

This work was supported by the National Natural Science Foundation of China (Nos. 50776055 and 51076084) 


\section{References}

[1]D. Kasao, T. Ito, Review of existing experimental findings on forced convection heat transfer to supercritical pressures, Cryogenics, 1989, 29(6): 630- 636.

[2]M. E . Shitsman, Impairment of the heat transmission at supercritical pressures, High Temperature, 1963, 1(2): 237-244.

[3]J. Licht, M. Anderson, M. Corradini, Heat transfer and fluid flow characteristics in supercritical pressure water, Journal of Heat Transfer, 2009, 31(7), 301-314 .

[4]M. van der Kraan, M. Peeters, M. V. Cid, et al, The influence of variable physical properties and buoyancy on heat exchanger design for near-and supercritical conditions, The Journal of Supercritical Fluids, 2005, 34(1): 99-105.

[5]J. D. Jackson, Fluid flow and convective heat transfer to fluids at supercritical pressure, Nuclear Engineering and Design, 2013, 264(SI : NURETH-14): 24-40.

[6]B. Shiralkar, P. Griffith, The effect of swirl, inlet conditions, flow direction, and tube diameter on the heat transfer to fluids at supercritical pressure, Journal of Heat Transfer, 1969, 3(92):465-471 .

[7]M. A. Styrikovich, T. K. Margulova, Z. L. MiropolSkii, Problems in the development of designs of supercritical boilers, Thermal Engineering, 1967, 14(6):5-9.

[8]K. Yamagata, K. Nishikawa, S. Hasegawa, et al . Forced convective heat transfer to supercritical water flowing in tubes, International Journal of Heat and Mass Transfer, 1972, 15(12):2575-2593.

[9]S. Mokry, I. Pioro, Development of supercritical water heat-transfer correlation for vertical bare tubes, Nuclear Engineering and Design, 2011, 241(4):1126-1136.

[10] Z. H. Li, D. L Zhang, Y. X. Wu, A New Criterion for Predicting Deterioration of Heat Transfer to Supercritical Water in Smooth Tubes, Proceedings of the CSEE, 2014, 34(35):6304-6309.

[11] N.L. Dichison, C.P.Weich, Heat transfer to supercritical water, ASME 80, 1958, 745-751

[12]J.W. Ackermann, Pseudo-boiling heat transfer to supercritical pressure water in smooth and ribbed tubes, Journal of Heat transfer, 1970, 490-498.

[13]A.A.Bishop, R.O. Sandberg, L.S.Tong, Forced convection heat transfer to water at near critical temperature and supercritical pressure, WCAP-2056-P, Part-Ш-B, February, 1964.

[14]N.S. Kondrat'ev, Heat transfer and hydraulic resistance with supercritical water flowing in tubes, Therm. Eng, 1969, 16 (8):73-77.

[15]B.S. Petukhov, V.S. Protopopov, V.A. Silin, Experimental investigation of worsened heat transfer conditions with the turbulent flow of carbon dioxide at supercritical pressure, High Temp. 1972, $10(2): 304-310$.

[16]V.S. Protopopov, V.A. Silin, Approximatemethod of calculating the start of local deterioration of heat transfer at supercritical pressure, High Temp, 1973, 11 (2):399-401.

[17]Z.H. Hu, Heat Transfer Characteristics of vertical upflow and inclined tube in the supercritical pressure and near-critical pressure region, Xi'an : Xi'an Jiaotong University, 2001. (in Chinese) . 